\title{
THE IMPLICATIONS OF HOW SCHOOL STAFF HANDLE INFORMATION FOR THE USAGE OF SCHOOL INFORMATION SYSTEMS
}

\author{
ADRIE J. VISSCHER \\ University of Twente, The Netherlands
}

\begin{abstract}
This chapter starts with a description of the various ways in which computer-assisted school information systems (SISs) can support school staff. Subsequently, the results of a review of the research concerning the features of information handling at teacher and at school management level are presented. In addition, some characteristics of decision-making in schools are portrayed. Finally, conclusions are drawn regarding the impact of SISs, and the way in which system usage (especially decision-making support) can be increased. Copyright $(1996$ Elsevier Science Ltd
\end{abstract}

\section{Introduction}

The power of computer-assisted school information systems is recognized worldwide. Although office automation provides benefits in many countries, however, the degree of system usage at the teacher and school management level proves to be limited (Visscher, 1995). Even when powerful SISs with enormous support capacities are at hand teachers and school managers benefit very little from them. These findings raise fascinating questions such as "why does not more intensive use occur at these levels?" and "how can more intensive system usage be promoted?"

In this chapter these questions are addressed by reviewing the research literature on information use by school staff and comparing the findings with the types of support SISs can provide. Stated in different terms, this chapter reports the degree to which the various features of SIS support characteristics match the ways in which school staff collect and process information. In the case of mismatch between the SISs and school staff behavior, ways to overcome the problem are explored.

The Potential of Computer-assisted School Information Systems

Computer-assisted information systems can fulfil a number of data processing functions in schools (Visscher, 1992). These can be summarized as follows: 
1. computer database update: recording changes in the organizational environment and changes within the organization itself (e.g. student application data are entered into the database);

2. information retrieval and document production: reporting on the organizational situation for operational activities that require little or no problem diagnosis because data lead directly to the action to be carried out (e.g. a computer report on those students who have applied, but still have to hand in some data relevant to the admittance decision);

3. decision-making support: some problems are structured, i.e., have a limited number of solutions and the way in which they have to be solved is known (e.g. constructing the timetable). In the case of more unstructured problems, when problem diagnosis and searching for solutions are important, the computer through flexible reporting can provide decision-makers with very specific information relevant to problem solving. One can analyze admittance trends over several years or relate features of admitted students to their school careers. As such, the computer can provide information about developments and problems and support the definition of school policy designed to solve the problems detected;

4. decision-making: the computer "itself" makes a decision on the basis of available information (e.g. when admittance criteria have been defined unambiguously, automatic admittance decisions are possible);

5. communication: mutually connected computers exchange messages and other data with other staff and other organizations (e.g. data on admitted students are distributed by the computer).

In addition to the general type of SIS described so far, a more specific kind of SIS has become available over the last two years. So-called Student Monitoring Systems consist of a set of instruments designed to evaluate long term student progress (students are tested once or twice a year). Strengths and weaknesses of individual students, student groups, and schools in certain subjects are assessed in reliable and valid ways (Gillijns, 1991). In the design of these systems much attention has been paid to the psychometric characteristics of the student tests in order to ensure that student progress is determined very accurately (which is impossible by means of the usual teacher marks). Student progress data collected by means of the designed student tests can be entered into the computer which thereafter produces student progress reports which can be used at both teacher and school management levels.

\section{Features of Information Management at Two School Levels}

Information management can occur at two levels: school manager and teacher. Features of information management at each of these levels are described in following sections.

\section{Information Management by School Managers}

Mintzberg (1989) typifies managers as sophisticated nerve centers of organizational information, looking for internal and external informers and disseminating information. They receive information from many different sources, among others from specific staff to whom only they 
have access by virtue of their organizational position. The information concerns internal organizational operations, external events, analyses in reports, ideas and trends, and pressures from consumers or interest groups. Managers restructure information for use in decision-making and build their own models of how the organization functions.

According to Mintzberg managers seek and use information that is current and comes in the form of "triggers". "Hot" information that moves quickly like a rumour is more important than absolutely correct information. Triggering information concerns concrete stimuli with no aggregations, but with tangible detail that when pieced together in the manager's mind illuminates issues. Mail information is not appreciated since it contains formal, lengthy, general, non-current information and does not trigger immediate management action. Since managers appear to verbally communicate 70 to $80 \%$ of their time, they prefer information that is transmitted by verbal media such as telephone and meetings.

They do not operate as reflective planners, but as adaptive information manipulators. Managers are often thought of in terms of stereotypical rational problem solvers, receiving relevant information from management information systems and other sources and making decisions on that basis. This image, however, proves to be a fairy tale (McPherson, Crowson, \& Pitner, 1986). Time consuming, profound problem analysis, the subsequent generation of alternative solutions, and an elaboration of the most suitable solution prove to be rare. Sproull (1981) states that managers lack the time and inclination to dig through data. Furthermore, they tend to read or hear information only once. Riehl, Pallas, and Natriello (1992) have reviewed the literature on how principals value certain types of information and how this influences their information use. They argue that especially the nature of the conditions under which principals work (work days filled with many brief episodes of unpredictable interactions with others) affects how they use information.

Principals can only devote short periods of time to the many different topics to which they have to pay attention. Since they have to react rapidly, they need information quickly and therefore receive most of it in informal ways (opinions, advice, anecdotes, hearsay, speculation, and even gossip). Although school life is complex, they desire "simple" information they understand and (think they) can rely on. As a result of their work place constraints and the limitations of the human information processing capacity they are inclined to use information that is communicated informally, verbally in face-to-face interactions, and quickly, and which is accompanied by an interpretation and is consistent with their understanding of and orientation to their administrative role. The collection and processing of formal information often takes too much time. Quantitative aggregated reports are therefore only used to a small degree (Sproull, 1981; Mintzberg, 1989). These findings imply that managers often make decisions based on insufficient information. However, making decisions in that way is preferred to not making decisions at all since at least something is done (Mintzberg, 1989).

According to Shangraw (1986) managers rely less on computer output than on other printed information. They prefer summary reports showing a bottom line, even when more detailed information is available. In addition, they make fewer interpretation errors when using these summaries.

Although managers do not use computer data very intensively Leithwood and Montgomery (1982) have shown that principals who frequently quantitatively analyze student and teacher performance (which nowadays is usually done in computer-assisted ways) operate more effective schools. Principals experience difficulties using quantitative/statistical data because they are untrained and inexperienced with this type of data. This unfamiliarity makes it difficult for them to determine the quality of the information and to interpret and use it for school improvement. 
This finding is in line with Riehl et al. (1992) who argue that principals who are comfortable with quantitative data on student outcomes, who trust them, and are trained to interpret them, are more likely to use these data.

Mintzberg (1989) contends that the characteristics of the information that managers rely on are in conflict with most formal information systems (ISs) that produce aggregated, precise, internal, historical information. According to him managers do not use all the formal information ISs produce for rational problem solving because of:

1. the poorness of formal ISs: a lot of qualitative information (politics, personality features, etc.) and formally non-transferrable information (like gestures, tone) is missing in them. Aggregated information is too general. Formal information often comes too late and its processing makes the required quick responses impossible. Moreover, it often is difficult to draw conclusions and base actions on the basis of formal information. What, for instance, statistics on the number of students passing the examinations say about the quality of instruction is unsure;

2. problems of organizational functioning: rigid organizational goals can result in inadequate organizational behavior, e.g., trying to raise profit figures without paying attention to other matters that are important in the long run. In addition, people may distort information for political reasons and only use information that strengthens their own position.

3. the limitations of the human mind: humans can only take a limited number of relevant information elements into account in decision-making. Moreover, the human brain often filters information in such a way that it fits with personal perception. The marketing division for instance interprets information in such a way that a problem becomes a marketing problem. As a result, some relevant information may be neglected.

ISs contain only a small part of all available and relevant information, of which the manager receives a subset, of which the brain only absorbs a subset, and of which only part is precise and relevant! Since much of the relevant information is in human instead of computerized memories, verbal information channels as well as printed/written information have to be used.

\section{Information Management by Teachers}

To portray the context of teachers' work, a description of their work conditions is presented, based on a situational analysis of the classroom by Huberman (1983). He typifies the work of teachers as multidimensional, since they have to carry out many different tasks such as present subject matter, react, organize, ask questions, stimulate, evaluate. Moreover, teachers have to pay attention to many different matters simultaneously: one student asks a question, another raises his finger to react, a third has not returned from the toilet yet, and some other students need attention because they misbehave.

Teachers have to manage uncertainty. The goals they try to achieve are ambiguous and the features of (the input of) student groups differ. Questioning the subject content taught, the teaching methods used and the effects of instruction in a specific teaching situation adds additional uncertainty (McPherson et al., 1986; van Vilsteren \& Visscher, 1987). Finally, the cause of disappointing results is difficult to determine from the many factors influencing instructional outcomes (e.g. teachers' and students' motivation and capacities, classroom climate). Huberman typifies achievement tests as "substitute indices"; while they are meant to indicate educational results, the degree to which test scores are actually attributable to instruction remains unsure. 
The teaching situation will always be uncertain; it can never be controlled perfectly. It is impossible to scientifically understand and explain everything that happens in it. Huberman refers to Lortie (1975) who observes that the mood of a teacher is important in determining the effects of his or her teaching behaviour: a well prepared lesson may not produce the desired results, whereas an unprepared lesson can prove to be very effective.

Since during each lesson period about 200 situational changes occur (Brophy \& Good, 1974) teachers do not have much time to reflect on what happens in the classroom and on their own role. Their primary goal is to solve the short term problem of how to attract the attention of students and how to promote their efforts. To teach is to a large extent "to improvise well;" to judge intuitively what should be done in a specific situation and use heuristics and "tricks" that have proven to work in the past.

Teachers prefer informal information from their own experience or from their colleagues because this information is quickly available, to the point, and fits with daily practice. Since colleagues share the same frame of reference they can provide each other with subjective recipes that "have worked very well for themselves."

Research indicates that teachers make decisions before (on instructional content, activities, and organization), during (react to unpredictable events) and after (evaluation) instruction. Riehl et al. (1992) have concluded that two conditions of teachers' work provide special constraints on their information handling. First, they receive much "fast-breaking news" (Stinchcombe, 1990) on the social and cognitive features from the many students with whom they have contact, which makes heavy demands on their information processing capacity. Second, there is little time in which teachers do not have contact with students, in which the overwhelming body of information on students can be processed, and in which strategies for its use can be developed.

Despite the constraints on their information use teachers do use a wide range of information about students. They react to the two aforementioned work conditions by using only the most salient information and reducing their need for information processing. Greater salience of information means that information is:

- generated by themselves;

- vivid, emotionally compelling, concrete and close to their own experience: personalistic/ qualitative instead of abstract/quantitative, and pertaining to social/behavioral as opposed to academic matters;

- presented in face-to-face interaction and continuously instead of with long or irregular intervals;

- presented in a format consistent with the format of other information;

- confirming their own experience;

- considered by teachers as necessary for their work; and

- linked to immediate courses of action.

The flood of data, in combination with little time for considering student needs and teaching objectives (an instructional decision about every two minutes) and the limited human information processing capacity, result in a reduction of the need for information processing. This is done by relying on instructional routines that have proven successful in the past, basing actions on a simple model of reality, and interpreting and using information rapidly and selectively (Shavelson \& Stern, 1981). In addition, certain techniques are used to simplify information collection and processing, such as collecting information on a sample of students as a point of reference for the whole student population. Students are evaluated quickly and on the basis of incomplete information. 
Just as in the case of principals, information quality in terms of reliability and validity proves to be less important than the speed with which information becomes available (Dorr-Bremme, 1983) and the degree to which information serves as a starting-point for actions. The perceived information quality is more important than its objective quality. Especially if theoretically correct information means that the information is not immediately accessible, the probability that it will be used is small; quantitative, computer-produced information falls into this category. In addition, it is usually less well understood and used than qualitative information. Information received by teachers must fit into how they work and into their frames of reference, typified as acting intuitively and appreciating information that can be used directly to reduce uncertainty. According to Riehl et al. (1992) instructional decisions are more based on teachers' own observations of student interactions and involvement than on diagnosing student needs and on standardized test scores.

On the basis of his research Pijl (1988) concludes that teachers have a global impression of a student (group) on the basis of which they choose a standard instructional strategy. As a result of their professional training and previous teaching experience they can choose from a tool kit of action plans. A chosen strategy encompasses a whole range of decisions concerning "what is done and how" which implies that many instructional decisions do not have to be made anymore because they are part of the global impression of the student group and the chosen action plan. Teachers do not feel in need of detailed information on student achievement after an instructional routine has been chosen. Only very radical changes in their opinion on a student (group) result in a switch to a different (but standard) approach.

Teachers tend to have relatively stable judgements about the academic ability and/or needs of students. Assessments made at the start of a school year usually change very little thereafter (Morine-Dershimer, 1978). An interesting question is to what degree teachers use information that becomes available after the first few months of a school year.

Summarizing the findings of the research on information handling by school staff there proves to be much similarity between the nature of information management by principals and teachers. Both have to make many decisions in a context of uncertainty and are burdened with information with little time to process and reflect on it. As a consequence, they reduce their need for information processing and use information selectively. Full rational behavior, in terms of choosing the best mode of operation for achieving explicit goals after having processed all relevant information, is rare. Many actions are uninformed or based on inaccurate information. The perceived quality of information is more decisive for its usage than its objective quality. There is a strong preference for up-to-date, quickly available, directly usable, informal, clear, and action triggering information.

\section{The Decision-making Capacity of Schools}

The congruence between an IS and its organizational context influences its impact (livari, 1992). Thus, how schools function as organizations, especially in terms of their decision-making capacity, affects the usage of SISs, especially in policy-making processes.

In the literature school personnel are portrayed as weak policy makers (e.g. Cohen, March, \& Olson, 1972; Weick, 1982) because of the political interests of those in the school who participate in decision making. Decision making situations function as "garbage cans" into which participants throw their individual, instead of organizational, problems and goals. Either decisions are put off or only those decisions that neither threaten any participant nor solve any 
problem are made. Weick (1982) also points to the fact that the link between decisions and their execution is not strong: many decisions are not, or only partially, executed.

Another factor believed to weaken the decision making capacity of school personnel concerns the fact that in the case of school organizational problems it is often difficult to determine cause, effect, and remedies. For example, the course and outcomes of the teaching-learning process are affected by many factors (such as the features of students, teachers, home situations, and societal patterns) of which the precise influence of any one is unknown. Although relations between factors may be found, in most cases it will be very difficult to determine "what causes what" and what should be done to achieve a desired result. Restated briefly, policy making at school level proves to be limited as a result of political interests of participants, the partial execution of decisions, and the difficulty to determine cause of and remedy for organizational problems.

We have determined some general features of schools with regard to decision-making. However, as Marx (1975) has demonstrated, the school does not exist. Schools vary in their policy making capacity. He has also shown that a school can be more able to develop school policy in one specific area of policy making (e.g., resources) than in another (e.g., instruction). Two of the five school organizational types Marx distinguishes are presented now to illustrate this perspective.

According to Marx many schools possess the features of the segmental school in which teachers operate as loose segments, taking care of their teaching task by cooperating little or not at all with colleagues. There is very little consultation and policy-making in this type of school. If it is done it mainly occurs at school management level and concerns the development of a resources policy. School policy making in other areas is rare.

In the fraternal school consultation among staff is intense at all school levels (management, subject departments, advisory school bodies, and school divisions). Subject departments are solid cooperative teacher groups fulfilling a pivotal function and actively developing instructional policy, which is also strongly stimulated by school management who itself develops policy in other areas (e.g., resources). Although a school never fully possesses the features of any one of Marx's school types the models show that schools can differ regarding their magnitude of policy making in different policy making areas.

The impact of introducing SISs on school policy making will vary in concordance with the degree to which the prerequisites for policy making are fulfilled. In case of a limited policy making capacity, the arrival of a powerful SIS certainly will not immediately lead to intensive computer-supported policy making. It is much more probable that much of the system's decision support capacity remains unutilized. A first condition for increased policy making then would be the alleviation of the cause of limited policy making through organizational development.

In schools more capable of developing school policy before the computer becomes available, the impact of a SIS may be enormous. These schools may be able to use computer information in all areas and at all school organizational levels, to support their decision making.

\section{The Impact of Computer-assisted School Information Systems}

In this final section some conclusions are drawn with respect to the impact of computerized SISs in terms of the degree to which school staff benefit from the various computer functions. Each computer function that has been described at the start of this chapter is related to the results of the research review on information handling in school organizations. Finally, to determine the probable impact of SISs, attention is paid to how information system usage may be maximized. 
The research review contained little about the registration, retrieval, and communication activities of teachers and school managers. This is probably due to the fact that almost no research has been done on these "lower order" school organizational activities. However, these three computer functions are relatively undisputed; their value has been proven frequently (Visscher, 1991, 1992, 1995). School staff efficiency benefits from the computer-supported possibilities to enter, retrieve (single entry-multiple use of data), and communicate data. School office staff and school managers, both of whom spend a lot of time on clerical activities (Visscher, 1992), benefit most from these three computer functions. Although teachers carry out less clerical work, however, they probably also use the computer-assisted possibilities to register (e.g. marks), retrieve (e.g. student progress reports) and communicate data, and as such operate more efficiently.

\section{Autonomous Computer-executed Decision-making}

Decisions in schools will probably not be made by computers to a large extent. However, this function enables the timely observation that something needs to be done (e.g. against truancy, budget depletion, poor student achievement) because certain school standards have been violated. What has to be done will in most cases be determined by school staff. One wonders to what degree this function will change schools. Even if school managers can benefit from this computer function (e.g. because a SIS indicates that the results of certain student groups are poor), they may not interfere a great deal in the territory of the rather autonomously operating teacher.

Moreover, the research review showed that teachers continuously collect informal information on what is going on in their classes and if necessary adapt their instructional behavior. At the time test scores and teachers' marks entered in a SIS indicate that some students are not doing well, these data may reflect an old situation that has changed a lot. In other words, for timely teacher actions, the informal information collected by teachers themselves is much more important than the formal information SISs produce.

This computer function probably does not fundamentally change the work of the management staff in non-instructional areas such as finance or personnel. Nevertheless, it has some value in those fields because it points to something that requires action and otherwise would not be done, or be done late. The international trend toward decentralization makes schools more autonomous in the fields of finance, personnel, and other resources. As a consequence, managing these policy areas will become more complicated for schools, and schools will likely become more vulnerable. Benefiting from this "warning light" computer function is one way to increase a school's management capacity in these policy areas.

\section{Decision-making Support}

The last computer function discussed supports school management and other school staff involved in decision making. This can be done by assisting in the solution of structured and unstructured problems. Support in finding solutions for structured problems is certainly valuable 
for school managers faced with complex allocation problems. They can determine better solutions (e.g. better timetables or student-lesson-group allocations) because the computer can determine many, if not all, possible solutions as a result of its enormous data processing capacity. The use of SISs for this activity saves precious management time and provides the opportunity to benefit from the best solution available for a structured problem. It is very probable that the latter influences school functioning positively.

SISs can also provide information relevant for coping with more "open" policy development problems that schools confront. This form of support, however, is not simple. It proves to be naive to expect that sophisticated SISs, because they can produce a lot of information previously not available, will directly and dramatically change schools. Weiss (in Alkin, 1990) points to the fact that we often talk about decision making as if information leads to decisions, whereas decisions are the product of enormous numbers of interacting variables, so many things besides information.

As a consequence of the portrayed characteristics of teacher work, the decision making support function for their daily teaching work is not expected to be very important. Teachers will always have to improvize in the uncertain classroom and the most important basis for instructional decision making will remain their own observations. It is interesting to note, however, that although the research literature indicates that the objective quality of information is not sufficient for its use, Dutch teachers very intensively use the more valid and reliable information on long term student progress produced by Student Monitoring Systems (Gillijns, 1991) (for more information on SMSs see the start of this chapter). Maybe the fact that they usually do not have time to systematically evaluate their results produces an appreciation of precise information on student achievement a few times a year. That information enables them to check whether their own observations and improvizations in the classroom have led to the desired results.

This chapter has described a situation in which school managers do not greatly benefit from the capacity of SISs to inform decision-making (Visscher, 1995). They neither make SIS-assisted analyses to investigate patterns in school phenomena nor use SISs for policy evaluation and simulation. This may be due to the fact that the usual circumstances of teaching and administrating do not permit informed dialogue, decision-making, action taking, and evaluation (Goodlad, 1975). Reflecting on how the school is doing in terms of trends, problems, and results is not often done by school managers. Thus, it is not surprising that SISs are not used for that work. School managers accommodate the constraints on the use of systematic information by lower levels of information use (especially by using informal information) and by rather uninformed decision making.

However, complete rational decision making with respect to complex, unstructured problems will never be possible. The complexity of organizational problems, the political factors involved, and the limitations of human information processing imply that the best to be achieved concerns "bounded rationality" and finding solutions that are satisfactory rather than "the best" (Simon, 1993).

Moreover, SISs alone will not bring universal happiness since they only contain part of the information that "drives the organization" (Mintzberg, 1989) and that school staff like to use. SIS information may be too old, too general, and too inaccessible. In combination with the formal, quantitative, and aggregated data that SISs produce, informal, qualitative, and detailed information is essential for decision making in schools. Just as it is dangerous to only base actions on informal data, formal information stored in SISs provides an insufficient basis for managing schools (see Sproull \& Zubrow, 1981). 
SIS output certainly will not directly lead to undisputed solutions for all unstructured problems, but it definitely enables more informed decision making by providing information on school organizational functioning, possible causes, and possible consequences of the various ways available to influence school organization. When data about students, personnel, finance, and similar factors have been stored in a computer database in such a way that relations between and among variables can be examined, the system can generate tailored, relevant information and as such enable more well-founded decisions. In the manual situation it is impossible to produce the same tailored information.

SISs also can be of help in evaluating the effects of policy decisions. The following are examples of relevant SIS information that can be used for making decisions in unstructured contexts.

1. Information on patterns in

- costs/budgets;

- teachers'/departments' results;

- student and staff absenteeism;

- student through flow; and,

- student achievement.

2. Information on the relationships between

- criteria for admitting students and the pass rates on the final examinations;

- student absenteeism and student achievement;

- student absenteeism and timetable characteristics (when are students playing truant most often?);

- lesson drop out and lesson group achievement; and,

- school examination scores and national examination scores per subject and per teacher.

3. Simulations of the implications of

- changes in student promotion criteria on student promotion figures;

- alternative methods for allocating financial resources; and

- alternative ways for allocating teaching periods to teachers.

4. Evaluations of whether

- truancy figures have decreased after the timetable has been changed;

- student results have improved after extra mathematics lessons have been given;

- student achievement reflects that school entrance criteria was lowered two years ago.

The fact that managers and other school staff involved in decision making use only limited information does not mean that we should not try, where possible, to increase the degree of rationality in their behavior. The following ways of increasing decision making support need to be considered.

1. Since the user's perception of the value of certain information proves to be crucial for its use, it is very important to show school managers how useful SIS information can be in policy making. Just as millions of people use computers for office work because they experience the advantages of doing so, experiencing the added value of computer-assisted decision making most probably will stimulate school leaders to use SISs for working on complex problems. The best strategy may be to start with small projects with a high success probability. If for example, a school's functioning is improved a certain amount on the basis 
of computer-produced information, this will encourage school staff to invest more time and energy in using these tools. Success breeds success.

2. Simon (1993) emphasized that while information is not a scarce resource, human attention and information processing capacity is limited. If we let computers produce all information they can produce, school staff will die as a result of information pollution. Research on information handling within schools has shown that the contents and nature of information influences its usage. SISs should operate intelligently, be selective, and only output information that is interesting and has the potential to improve school quality.

3. Computer output must also be appealing, easily retrieved, readily analyzed, and an invitation to take action. Current SISs often do not meet these requirements. It therefore would be helpful if the output is manipulated by selected school staff having a specific information handling task, before being distributed to other school staff. More preferable would be that we build SISs that make it easy to retrieve all kinds of data and that produce information that is understood easily. The barriers for retrieving and processing valuable SIS data should be made as small as possible, and hence the probability that this information is used will be as great as possible.

4. The description of the decision making capacity of school personnel showed that although school personnel differ in their policy making capacity, they in general are not considered to be very forceful policy developers and evaluators. Computer-assisted policy making and evaluation touches the whole school organization. In many schools integrating SISs fully in their policy development requires fundamental organizational development demanding a lot of energy from school staff. Organizational innovation and evolution should bring them to a level of organizational functioning that enables them to decide which SIS information they need for decision making; retrieve at least part of the information they need from a SIS; interpret the data in such a way that it can be used for decision making; use the information for developing, implementing, and evaluating school policy.

Achieving full system utilization resulting in improvement in organizational performance is enormously difficult, even when a high quality SIS is available. Essential to the success of this innovation is the degree to which we are able to design and implement SISs that produce interesting, valuable, and accessible information that matches the nature and information needs of schools. School staff need to be convinced of the added value of these systems, and ways must be found to prepare them for full system usage. If this can be accomplished it may be possible to change schooling in a very important way.

\section{References}

Alkin, M. C. (1990). Debates on evaluation. Beverly Hills: Sage Publications.

Brophy, J., \& Good, T. (1974). Teacher-pupil relationships. New York: Holt, Rinehart \& Winston.

Cohen, M. D., March, J. G., \& Olson, J. P. (1972). A garbage-can model of organizational choice. Administrative Science Quarterly, 17, 1-25.

Dorr-Bremme, D. (1983). Assessing students: Teachers' practices and reasoning. Los Angeles: California University. Gillijns, P. (1991). Leerlingvolgsystemen [Student Monitoring Systems]. Tilburg: Zwijssen.

Goodlad, J. I. (1975). The dynamics of educational change: Toward responsive schools. New York: McGraw-Hill.

Huberman, A. M. (1983). Répertoires, recettes et vie de classe: Comment les enseignants utilisent l'information. Education et Recherche, 5(2), 157-177.

Iivari, J. (1992). The organizational fit of information systems. Journal of Information Systems, 2(I), 3-29.

Leithwood, K. A., \& Montgomery, D. J. (1982). The role of the elementary school principal in program improvement. Review of Educational Research, 52, 309-339. 
Lortie, D. (1975). School teacher: A sociological study. Chicago: University of Chicago Press.

Marx, E. C. H. (1975). De organisatie van scholengemeenschappen in onderwijskundige optiek. [The organization of comprehensive schools from an educational point of view]. Groningen: Wolters-Noordhoff.

McPherson, R. B., Crowson, R., \& Pitner, N. J. (1986). Managing uncertainty: Administrative theory and practice in education. Columbus: C. E. Merrill Publishing Company.

Mintzberg, H. (1989). Mintzberg on management. New York: Free Press.

Morine-Dershimer, G. (1978). How teachers "see" their pupils. Educational Research Quarterly, 3(4), 43-52.

Pijl, S. J. (1988). Het gebruik van diagnostische informatie [The use of diagnostic information]. Unpublished doctoral dissertation, University of Groningen, Groningen.

Riehl, C., Pallas, G., \& Natriello, G. (1992). More responsive high schools student information and problem-solving. Paper presented at the Annual Meeting of the American Educational Research Association, San Francisco.

Shangraw, R. F. (1986). How public managers use information: An experiment examining choices of computer and printed information. Public Administration Review, 46, 506-515.

Shavelson, R. J., \& Stern, P. (1981). Research on teachers' pedagogical thoughts, judgements, decisions, and behaviour. Review of Educational Research, 51(4), 455-498.

Simon, H. A. (1993). Decision making: Rational, nonrational, and irrational. Educational Administration Quarterly, 29(3), 392-411.

Sproull, L. S. (1981). Managing education programs: A micro-behavioral analysis. Human Organization, 4O(2), 113-122.

Sproull, L. S., \& Zubrow, D. (1981). Performance information in school systems: Perspectives form organization theory. Educational Administration Quarterly, 17(3), 61-79.

Stinchcombe, A. L. (1990). Information and organizations. Berkeley/Los Angeles/Oxford: University of Califomia Press.

van Vilsteren, C. A., \& Visscher, A. J. (1987). Schoolwerkplanning: mogelijk in schoolorganisaties? [School work planning: possible in school organizations?] In B. Creemers, J. Giesbers, C. van Vil-Steren \& C. van der Perre (Eds.), Handbook schoolorganisatie en onderwijsmanagement (pp. 6120-6124). Alphen aan den Rijn: Samsom.

Visscher, A. J. (1991). School administrative computing: A framework for analysis. Journal of Research on Computing in Education, 24(1), 1-19.

Visscher, A. J. (1992). Design and evaluation of a computer-assisted management information system for secondary schools. Unpublished doctoral dissertation, University of Twente, Enschede.

Visscher, A. J. (1995). Computer-assisted school administration and management: where are we and where should we go? In B. Z. Barta, M. Telem \& Y. Gev (Eds.), Information technology in educational management (pp. 15-26). London: Chapman \& Hall.

Weick, K. E. (1982). Administering education in loosely coupled schools. Phi Delta Kappan, 63(10), 673-676. 